\title{
www.deswater.com
}

1944-3994/1944-3986 @ 2009 Desalination Publications. All rights reserved

\section{Transparent exopolymer particles: Potential agents for organic fouling and biofilm formation in desalination and water treatment plants}

\author{
Edo Bar-Zeev ${ }^{\mathrm{a}}$, Ilana Berman-Frank ${ }^{\mathrm{a}}$, Boris Liberman ${ }^{\mathrm{b}}$, Eyal Rahav $^{\mathrm{a}}$, Uta Passow ${ }^{\mathrm{c}}$, \\ Tom Berman ${ }^{\mathrm{d}^{*}}$ \\ ${ }^{a}$ Mina and Everard Goodman Faculty of Life Sciences, Bar Ilan University, Ramat Gan, Israel \\ ${ }^{b}$ I.D.E., Kadima, Israel \\ ${ }^{c}$ Marine Science Institute, University of California, Santa Barbara, 93106 CA, USA \\ ${ }^{d}$ Kinneret Limnological Laboratory, Israel Oceanographic and Limnological Research, POB 447, Migdal 14950, Israel \\ Tel+97246909476; email: tomdebberman@gmail.com; tberman@ocean.org.il
}

Received 10 November 2008; Accepted 1 March 2009

\begin{abstract}
A B S T R A C T
Transparent exopolymer particles (TEP) are ubiquitous in marine and freshwaters, and have been subject to intensive study by oceanographers and limnologists over the past 15 years. These microscopic organic particles (visualized by Alcian Blue staining for acid polysaccharides) may be considered a planktonic form of exopolymeric substances (EPS). Two aspects relating to the potential involvement of TEP as important agents in organic fouling and biofilm formation on membranes in desalination and wastewater treatment plants were investigated: the efficiency of pretreatment processes in decreasing the amounts of TEP reaching the RO membranes at the Adom desalination plant, Ashkelon; and the active involvement of TEP in the early stages of biofilm formation. This study revealed that although pretreatment at the desalination plant lowered the levels of water quality parameters such as chlorophyll and SDI by $\sim 90 \%$ relative to input, TEP concentrations were only decreased by $\sim 30 \%$ upstream of the RO membranes. To follow TEP in the early stages of biofilm formation, glass slides were suspended in seawater over several days. Slides were removed daily, stained with Alcian Blue (for TEP) and DAPI (for bacteria) and examined under the microscope with Nomarski light illumination and UV-epifluorescence. By $18 \mathrm{~h}$, we observed many areas stained with Alcian Blue as well as some individual bacteria on the surface. The Alcian Blue stained areas were not due to EPS proliferated by bacteria attached to the surface but derived from TEP originally in the feed water. After $18 \mathrm{~h}$, there were increasing areas stained with Alcian Blue and greater numbers of bacteria growing on stained and unstained areas of the substrate surface. Taken together, these results imply that TEP in source waters are indeed likely to be key players in the establishment and subsequent development of biofilm on membranes and that pretreatment technology does not effectively remove these particles from reaching membranes. Recognition of the importance of TEP in aquatic biofilm formation could lead to the use of TEP as an indicator of the efficacy of current pretreatment methods as well as to the development of improved techniques to remove these particles upstream of membranes in desalination and wastewater treatment plants.
\end{abstract}

Keywords: Transparent exopolymer particles; TEP; EPS; Biofilm formation; Membrane desalination pretreatment 


\section{Introduction}

Biofouling and biofilm growth on filtration membranes and other surfaces is a major problem in desalination and wastewater treatment plants [1-3]. To minimize organic fouling and scaling, source waters pass through various pretreatment stages such as flocculation, sedimentation, filtration or UV irradiation prior to reaching the membranes.

Investigators of fouling in aquatic systems have long inferred the involvement of organic colloidal material, polysaccharides, proteins and other unknown components of natural organic matter (NOM) in the preconditioning of surfaces for biofilm development [4-7]. There is an extensive literature in the membrane/desalination field on fouling of membranes by biomacromolecules and biofilm formation and many studies in the last $5-10$ years have elucidated the mechanisms of proliferation of exopolymeric substances (EPS) and biofilm formation [8-12]. These studies showed that within the first few minutes of contact between natural waters on different surfaces, an uncharacterized "molecular fouling" appeared that was hypothesized to play a crucial role in the initiation of biofilm development on those surfaces. Recently Berman and Holenberg [13] and Berman and Passow [14] proposed that transparent exopolymer particles (TEP) which are found in large numbers in marine and freshwaters, play a major role in aquatic biofilm formation and development on membranes and other surfaces.

The aims of this study were to investigate two aspects of the potential involvement of TEP as important agents in organic fouling and biofilm formation on membranes in desalination plants. First, over a 7-month period, we monitored the efficacy of various pretreatments in a full-scale $\left(300,000 \mathrm{~m}^{3} \mathrm{~d}^{-1}\right.$ capacity) seawater reverse osmosis plant to lower TEP as compared to other water quality parameters such as silt density index (SDI) and chlorophyll $(\mathrm{Chl})$. Second, to determine the relative importance of seawater TEP and bacteria in the early stages of biofouling, a series of laboratory experiments was carried out using a newly developed staining procedure to follow details of the attachment of these particles to surfaces.

\section{What are TEP?}

In 1993 Alldredge et al. [15] reported a high abundance of previously undetected, microscopic transparent particles in seawater that were visualized by staining with Alcian Blue, a dye specific for acid mucopolysaccharides. These were dubbed "transparent exopolymer particles", or TEP. It quickly became evident that TEP are ubiquitous in freshwater and marine environments and play impor- tant roles in these ecosystems [16]. In most natural waters, TEP have been observed in high abundance, from $\sim 10^{5}$ to $\sim 10^{7}$ particles $\mathrm{L}^{-1}$. As described in the oceanographic and limnological literature, TEP range in size from $\sim 0.4 \mu \mathrm{m}$ (the nominal pore size of the filters on which these particles are collected prior to staining) to $\sim 100-200 \mu \mathrm{m}$. Thornton et al. [17] have also reported the presence of Alcian Blue staining, acid polysaccharide colloids ( $>30,000$ Dalton $<0.4 \mu \mathrm{m}$ ) in natural waters. TEP are deformable, gel-like particles suspended in the water mass and appear in many forms; amorphous blobs, clouds, sheets, filaments or clumps. In some aquatic environments, TEP form abiotically from dissolved organic exudation products by processes of coagulation and gelation [18-20] or by turbulence and bubble adsorption [21]. Considerable amounts of TEP are also produced from the gelatinous envelopes surrounding diatoms and other algae [22] and from bacterial mucous [23]. TEP may also be formed during senescence by algae and cyanobacteria [24,25].

TEP may be considered as "macro-colloids", and have also been termed "macrogels" [26]. The presence of highly surface active polymers containing fucose and rhamnose $[16,20,26]$ in TEP explains the strong tendency of these particles to form metal ion bridges and hydrogen bonds [27]. As a result, TEP are about 2 to 4 orders of magnitude more sticky than phytoplankton or mineral particles, have a high probability of attachment upon collision $(16,20,27$, 28], and are likely to play an important role in particle aggregation in open water and in coating natural surfaces [26]. Many TEP provide a nutritious and sticky organic substrate for colonization by bacteria and other microorganisms [29-31] and thus form an ideal platform to transport planktonic bacteria to surfaces. Because TEP are rich in surface active, acidic polysaccharides [20,21], many other substances, including proteins, nucleic acids or trace elements may be associated with these gel-like particles [16]. In summary, TEP may be characterized as microscopic $(>0.4 \mu \mathrm{m})$ transparent particles, ubiquitous in marine and freshwaters, that constitute a subgroup of planktonic EPS. Although numerous studies have focused on the polysaccharide-containing EPS matrix in biofilms adhering to surfaces $[11,12,32,33$,$] , the potential involve-$ ment in aquatic biofouling of TEP in source waters has yet to be investigated $[13,14]$.

It should be noted that TEP are not the only kind of microscopic transparent organic particles present in both marine and freshwaters. Another class of small particles that stains yellow with the nucleic acid stain DAPI was reported by Mostajir et al. [34]. Subsequently, Long and Azam [35] described a class of protein-containing, transparent particles in seawater observed upon staining with Coomassie Blue. Because no multiple staining techniques are presently available it is quite possible that some, if not most, of these transparent organic particles may contain 
varying amounts of polysaccharide, protein and/or nucleic acid constituents.

\section{Methods}

\subsection{Monitoring TEP, chlorophyll (Chl) and Silt Density Index (SDI) at the Adom Ashkelon desalination plant}

To monitor the efficiency of pretreatment at the Adom desalination plant, Ashkelon, Israel, water samples (5 L) were collected at key locations in the streamflow from source water input to the RO membranes: (1) on-shore sampling point for coastal seawater (intake $1000 \mathrm{~m}$ offshore); (2) after addition of flocculation reagents, mainly $\mathrm{Fe}_{2}\left(\mathrm{SO}_{4}\right)_{3}$; (3) before sand filtration; (4) after sand filtration; (5) before the micronic, cartridge filter; (6) after the micronic, cartridge filter (Fig. 1).

The concentrations of TEP and Chl were determined at each of the above sampling points on the following dates in 2008: 29 April, 25 May, 1 June, 13 July, 4 September and 20 October. SDI levels were measured only at the intake (1) and after the micronic filter (6).

\subsection{Analysis of TEP and Chl concentrations and SDI}

TEP concentrations in seawater were measured with Alcian Blue using the spectrophotometric assay developed by Passow and Alldredge [36]. The TEP concentrations were calibrated with gum xanthan, GX (an acid polysaccharide standard) and expressed as $\mu \mathrm{g}$ GX equivalents $\mathrm{L}^{-1}$. Chlorophyll was extracted into $90 \%$ acetone and determined fluorometrically [37]. (Note, this assay actually determines only chlorophyll $a$, by far the predominant form of this pigment in natural waters). SDI was measured online at the Adom desalination plant.

\subsection{TEP and bacterial adhesion experiments}

Coastal seawater was sampled from the intake of the Adom desalination plant and, after $\sim 1 \mathrm{~h}, 2$-L portions were placed in a series of sterilized and sealed glass flasks in the laboratory at Bar Ilan University. Precleaned and sterilized glass microscope slides were suspended from

\begin{tabular}{lccccc}
1 & 2 & 3 & 4 & 5 & 6 \\
\hline $\begin{array}{l}\text { Source } \\
\text { water }\end{array} \rightarrow \begin{array}{l}\text { Post- } \\
\text { ferric } \\
\text { sulfate }\end{array}$ & $\begin{array}{l}\text { Pre- } \\
\text { sand } \\
\text { filter }\end{array} \rightarrow \begin{array}{l}\text { Post- } \\
\text { sand } \\
\text { filter }\end{array} \rightarrow \begin{array}{l}\text { Pre- } \\
\text { micronic } \\
\text { filter }\end{array}$ & $\begin{array}{l}\text { Post- } \\
\text { micronic } \\
\text { filter }\end{array}$ \\
\hline
\end{tabular}

Fig. 1. Sampling locations at the Adom desalination plant. 1 coastal seawater "source water" on-shore sampling point; 2 after addition of flocculation reagents; 3 before sand filter; 4 after sand filtration; 5 before the micronic cartridge filter; 6 after the micronic cartridge filter. the stopper of each flask in the water which was incubated at room temperature $\left(\sim 22-24^{\circ} \mathrm{C}\right)$ and gently stirred throughout the experiment. Slides from separate flasks were sampled after 18, 48, 72, 96 and 168 h. At each sampling time, slides were removed for staining to check for TEP and bacterial adhesion.

Each slide was transferred to a glass Petri dish, stained with $0.02 \%$ Alcian blue for $7 \mathrm{~min}$ and gently rinsed twice by dipping in deionized, distilled water. Following this, the slide was stained by covering the surface with $10 \mu \mathrm{l}$ of 4',6-diamidino-2-phenylindole (DAPI, concentration $3 \mu \mathrm{g} \mathrm{ml}^{-1}$ ) for $7 \mathrm{~min}$ in the dark and rinsed twice as described above. The slides were then viewed first under brightfield illumination to reveal Alcian Blue stained areas probably deriving from adhesion of TEP to the surface, and then under UV epifluorescence to observe DAPI stained bacteria [38].

TEP and Chl concentrations were also assayed in the water of the flasks, initially and at each of the sampling times.

\section{Results and discussion}

4.1. Pretreatment impact on TEP levels in an operational desalination facility

In order to check the efficiency of existing pretreatment technology in removing TEP from the flow stream at a full-scale seawater reverse osmosis plant, we monitored TEP levels at various pretreatment stages at the Adom desalination plant that has been operational since 2005 (Fig. 1). Concomitantly, in the same water samples, we measured $\mathrm{Chl}$ concentrations (a proxy for the presence of algal cells that may also cause biofouling) and SDI as additional indicators of pretreatment efficiency.

Over the course of our study, the concentrations of TEP and $\mathrm{Chl}$ in the source water varied seven-fold and seventeen-fold, respectively (Table 1). In order to compare the results from different sampling dates, each of the parameters was normalized to its value in the source

Table 1

TEP and chlorophyll in source water at the Adom desalination plant

\begin{tabular}{lll}
\hline Date & TEP & Chl \\
\cline { 2 - 3 } & $\mu \mathrm{g} \mathrm{GX} \mathrm{eq.L^{-1 }}$ & $\mu \mathrm{g} \mathrm{L}^{-1}$ \\
\hline 25 May 08 & 542 & 0.18 \\
1 Jun 08 & 140 & 0.14 \\
13 Jul08 & 254 & 0.53 \\
4 Sep 08 & 176 & 0.20 \\
21 Sep 08 & 76 & 0.03 \\
15 Dec 08 & 98 & Not determined \\
\hline
\end{tabular}




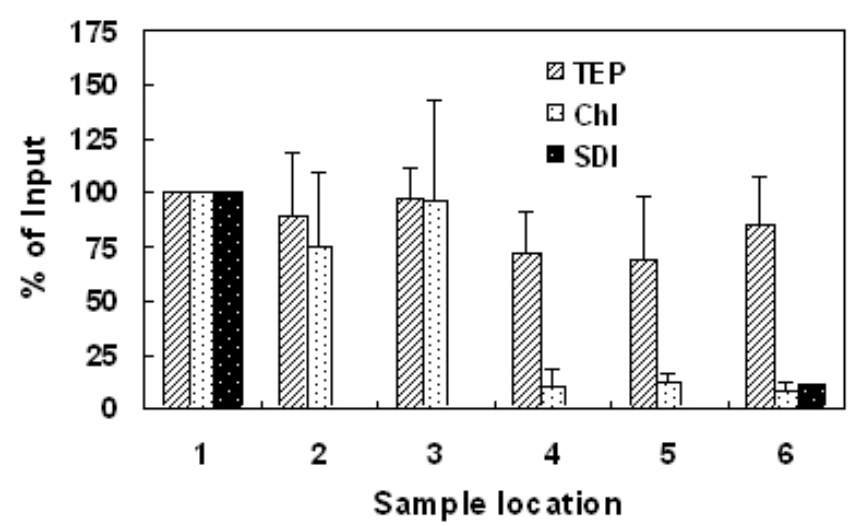

Fig. 2. Effect of pretreatment stages on concentrations of TEP, Chl and SDI (normalized to input concentrations as 100\%) at the Adom desalination plant. Mean and standard deviation of six sampling dates from May through September 2008. See Fig. 1 for sampling locations.

water input, taken as 100\%. In Fig. 2 we show the overall mean and standard deviation of TEP, Chl and SDI levels as percentages relative to the seawater input (100\%), measured at six locations in the streamflow at the Adom plant on six sampling dates from May through October 2008. On average, TEP concentrations in the input seawater were diminished by $27 \%( \pm 19)$ after passing the stage of the sand/ mixed-bed filter (Fig. 2). By comparison, Chl and SDI dropped by $90 \%( \pm 8)$ and $90 \%( \pm 2)$, respectively.

Based on the above results, we conclude that although the sand filter functioned very effectively to lower the levels of $\mathrm{Chl}$ and SDI, it was considerably less efficient in removing TEP from the streamflow reaching the RO membranes. We observed that when the concentrations of TEP in the source water were low (e.g. Sept. 2008), the sand filter was least effective, reducing TEP levels by only a few percent. At present, we do not know whether the TEP observed after sand filtration was derived solely from the source water or whether some of these particles were released from the sand filter medium.

Subsequent to the sand filtration step, TEP concentrations did not decrease further and, in fact, tended to rise after passing through the cartridge filter prior to reaching the RO membranes (Fig. 2). Although the reason for this consistent increase is unclear, we suspect that it may have been caused by TEP formation due to turbulence in the water stream passing through the cartridge filters [21]. In contrast to TEP, Chl levels remained constant after the sand filter until the RO membranes.

\subsection{TEP: Adhesion to surfaces}

We ran five experiments in which we suspended precleaned, sterilized glass microscope slides in untreated
Mediterranean coastal seawater over several days and followed the extent of TEP and bacterial cell adhesion to the slides. Here we show the slides from an experiment begun on 13 July 2008, similar results were obtained in all the other experiments.

A 2-day sequence of early biofilm formation on glass slides is illustrated in Fig. 3. Within 18 h, when viewed with Nomarski light illumination, Alcian Blue staining revealed many prominent blue areas on the slide surface that could only have come from the initial adherence of TEP in the seawater (Fig. 3, top left). Additionally, some scattered, individual bacteria, not associated with TEP, could be seen sticking to the slide surface. A few isolated bacteria were also visible on the Alcian Blue stained areas. These bacteria may have been original "residents" of the TEP particles prior to adhesion, or may have grown "in situ" subsequently. We also observed occasional algal cells attached to the surface (not shown in Fig.3).

Bacteria stained with DAPI were more clearly seen under UV epifluorescent illumination (Fig. 3, top right); under these conditions, Alcian Blue stained areas should have been invisible. Here again, we could discern individual bacteria adhering to the surface in areas not seen to be covered by TEP under light illumination (Fig. 3, top left), with only a very few bacteria on the Alcian Blue stained areas. Under UV epifluorescence, some, but not all, of the areas seen with blue stain in visible illumination also showed a definite, relatively faint, DAPI coloration (Fig. 3, top right). This observation suggests the possibility that nucleic acid molecules (DNA or RNA) were adsorbed or otherwise associated with TEP in these samples.

The surface area covered by Alcian Blue stain was considerably greater than that by individual bacterial cells (Fig 3, top left and right). Clearly the Alcian Blue stained areas observed on the slides could not have been EPS proliferated by surface attached bacteria within a brief $18 \mathrm{~h}$, but must have been "planktonic" TEP in origin. We observed that few, if any, of the single, attached bacteria were surrounded by any Alcian Blue staining EPS on slides sampled at $18 \mathrm{~h}$.

Slides examined after $18 \mathrm{~h}$ showed increasing and larger Alcian Blue stained areas with more associated bacteria as well as greater numbers of bacteria adhering to unstained surfaces (Figs. 3, bottom left and right). When examined under high magnification some of the single bacterial cells were seen to be surrounded by a thin layer of Alcian Blue stained material, presumably mucilageanous, capsular EPS.

With increasing time of incubation, the Alcian Blue stained areas became larger and more heavily coated with bacteria (images not shown). We also observed increasing amounts of algal cells (mainly diatoms such as Chaetoceros sp., Rhizosolenia sp. and Nitzschia sp.) adhering to the slides. In untreated seawater, algae can certainly be a 

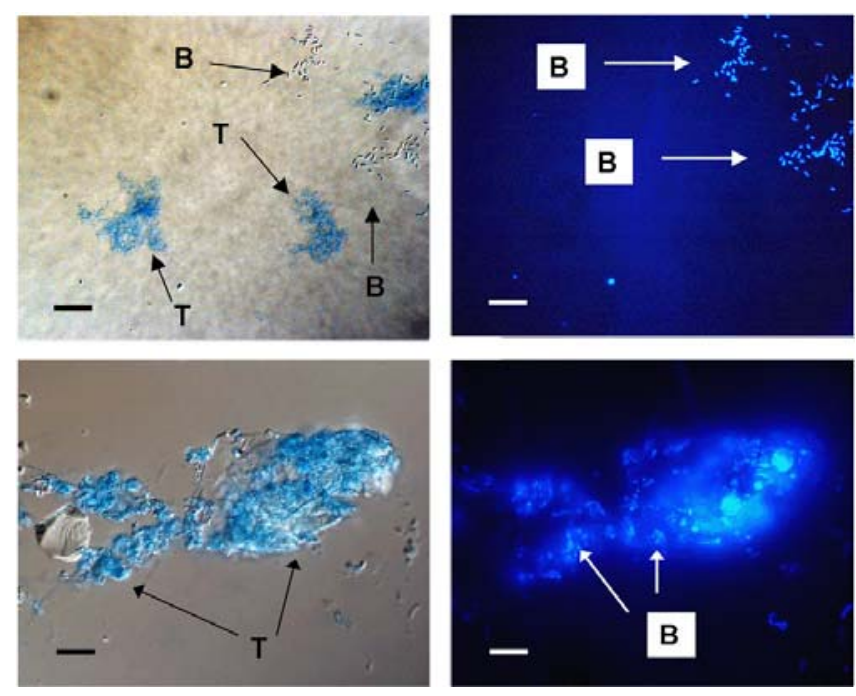

Fig. 3. TEP and bacterial involvement in early stages of biofilm formation on glass surface in coastal seawater. T, TEP; $\mathrm{B}$, bacterial cells. Scale bar $=10 \mu \mathrm{m}$. Top left: TEP (Alcian Blue stain), viewed with Nomarski illumination, at $18 \mathrm{~h}$. Note the isolated bacteria also adhering to the surface. Top right: Bacterial cells viewed with DAPI stain, under epifluorescence at $18 \mathrm{~h}$. Bottom left: TEP viewed Alcian Blue stain, Nomarski illumination, at $48 \mathrm{~h}$. Bottom right: DAPI stain, viewed under epifluorescence at $48 \mathrm{~h}$. Note the amorphous DAPI staining of the TEP particle, indicating that nucleic acids may also be constituents of this particle.

major cause of biofouling [39]. However, as we have shown above, pretreatment at the Adom plant very drastically reduced the levels of $\mathrm{Chl}$ reaching the $\mathrm{RO}$ membranes and therefore, given adequate pretreatment, algal cells should not be a factor in biofilm development on membranes.

$\mathrm{Chl}$ and TEP concentrations in the seawater used in this experiment were initially $0.53 \mu \mathrm{g} \mathrm{Chl} \mathrm{L}{ }^{-1}$ and $254 \mu \mathrm{g}$ GX equivalents $\mathrm{L}^{-1}$ respectively. Chl steadily decreased over the 7 days of the experiment, in contrast to TEP levels (Table 2). Clearly there were adequate pools of TEP and algal cells to stick to the slides, given the large volume of water relative to slide surface area.

Our observation that some of the TEP areas, identified under Nomarski illumination by their staining with Alcian Blue, were also visible under epifluoresence as DAPI stained areas, is perhaps the first direct evidence that nucleic acids may be associated with TEP in addition to polysaccharides. The diffuse nature of the DAPI staining might indicate that the nucleic acid signal was derived from molecules of DNA or RNA adsorbed to these particles rather than from discrete "packages" of nucleic acid in the form of virus or bacteria. Recent studies have indicated that, in addition to a major polysaccharide component, nucleic acids and proteins are also present in
Table 2

TEP and chlorophyll in time course flasks

\begin{tabular}{|c|c|c|}
\hline Day & $\begin{array}{l}\text { TEP } \\
\mu \mathrm{g} \text { GX eq. } \mathrm{L}^{-1}\end{array}$ & $\begin{array}{l}\text { Chl } \\
\mu \mathrm{g} \mathrm{L}^{-1}\end{array}$ \\
\hline 0 & $254 \quad(2)$ & $0.53(0.07)$ \\
\hline 1 & $330 \quad(34)$ & $0.42(0.01)$ \\
\hline 2 & Not determined & $0.39(0.01)$ \\
\hline 3 & $303 \quad(28)$ & $0.20(0.17)$ \\
\hline 4 & $247 \quad(21)$ & Not determined \\
\hline 7 & $232 \quad(26)$ & $0.09(0.07)$ \\
\hline
\end{tabular}

SD given in parentheses.

biofilm EPS [40]. We suspect that many of the TEP found in natural waters may also have some protein or peptide components. As noted, transparent organic particles similar to TEP, but stained with the protein stain Coomassie Blue have been found in both marine [35] and freshwater [24].

\subsection{TEP and biofilm development}

Although it has been suggested that TEP could be important in the process of biofilm formation in desalination and wastewater treatment plants $[13,14]$, to the best of our knowledge the present study provides the first experimental and observational evidence to substantiate this claim. In this study we have shown that, together with isolated, individual bacterial cells, TEP in coastal seawater adhered to surfaces within several hours of exposure. Over the next 1 to 5 days we observed that these TEP derived areas became increasingly colonized by bacteria. We also noted that by $48 \mathrm{~h}$ some of the single bacteria began to proliferate EPS (as visualized with Alcian Blue), but that this covered only a very small area of the surface compared to that originating from TEP.

At present, we have no way of discriminating between a "classical" EPS matrix, generated by growing biofilm bacteria [11], and EPS derived from planktonic TEP in the overlying water. However, because we observed relatively large Alcian Blue stained areas on the glass surface after $18 \mathrm{~h}$ with only a few isolated bacteria (Fig. 3), it seems reasonable to conclude that, at this early stage of biofilm development, most of the EPS areas visualized by this dye originated from TEP in the water flowing over the surface. These observations strongly indicate the direct participation of TEP in the initial stages of biofouling and biofilm formation. Moreover, planktonic TEP in natural waters are often colonized by bacteria [28-31] and, as noted, we also observed some bacteria growing on the Alcian Blue stained surfaces. Whether the indigenous TEP bacteria take part in subsequent development of the 
biofilm after the particles adhere to surfaces is unknown. Although experimental evidence is lacking as yet, we suggest that as biofilm develops, "planktonic" TEP will continue to adhere and accumulate on the growing biofilm surface.

The physical and chemical processes involved in organic fouling of membranes have been studied in considerable detail [6-10]. These studies have consistently indicated that adhesion of acidic polysaccharides and other organic macromolecules and colloids in the feed water is a major factor in conditioning membrane surfaces in the initial phase of fouling. Macromolecular and colloidal forms of polysaccharides and proteins have been identified as the most problematic foulants in many feed waters [7] and compounds such as alginate (an acid polysaccharide) have been used as model organic foulants in several of these studies $[9,10]$. We suggest that in the subsequent phases of aquatic biofouling on membranes and other surfaces, the relatively large particles $(>0.4 \mu \mathrm{m}$ $<100 \mu \mathrm{m}$ ) of TEP in the overlying water play a significant role. It is important to note that the involvement of TEP in the early stages of biofilm formation does not exclude, but rather supplements, other known mechanisms of biofilm development that undoubtedly occur, such as attachment of individual bacterial cells, EPS proliferation, quorum sensing [41], gene transfer [42], cell death and lysis.

\section{Conclusions and recommendations}

The important conclusion from our monitoring study of TEP at the Adom desalination plant is that despite pretreatment, which effectively removed considerable loads of particulate matter from the input source water, high levels of TEP that could be important in biofilm formation were still present in the streamflow reaching the RO membranes. A similar situation probably occurs in many other desalination and wastewater treatment facilities. Additionally, our results, showing the direct involvement of TEP in the early stages of biofilm development, indicate that any effective means of decreasing the amounts of TEP in the water reaching membranes should mitigate the severity of biofouling and biofilm accumulation.

We also suggest that routine monitoring of TEP concentrations subsequent to various stages of pre-treatment could be an effective management tool in wastewater treatment and desalination plants. Determining the efficiency of any given pre-treatment technology (filtration, sedimentation, UV-irradiation, etc) in lowering TEP concentrations can give manufacturers valuable insight into the performance of their products. Also, using TEP levels as an additional criterion for pre-treatment efficiency may prove cost-effective at the design and pilot plant stages of new desalination or water treatment facilities.

Clearly there is a need for more focused, applied research on the characteristics of TEP and other kinds of aquatic transparent organic particles in view of their potential roles in biofouling and biofilm development. Because these characteristics vary seasonally and in different aquatic environments, it will be important to define the physicochemical properties of TEP specific to each input source in order to develop optimal pretreatment technologies to minimize the amounts of these particles reaching membranes and other sensitive surfaces.

\section{Acknowledgements}

We are grateful to three anonymous reviewers for their helpful comments. We thank I.D.E. for granting us access to the Adom desalination plant, Ashkelon, Israel, and the assistance of Grigory Shtelman and Sergei Shatsman in sampling at the plant and providing SDI data. Part of this study (to T.B.) was funded within the framework of the Mayim Consortium, Magnet Programs, Office of the Chief Scientist, Israel Ministry of Industry, Trade and Labor.

This research is part of the $\mathrm{PhD}$ thesis requirements for Edo Bar-Zeev, who is supported by a President's Scholarship from Bar Ilan University.

\section{References}

[1] H-C. Flemming, G. Schaule T. Griebe, J. Schmitt and A. Tamachkiarowa, Biofouling the Achilles heel of membrane processes. Desalination, 113 (1997) 215-225.

[2] H-C. Flemming, Reverse Osmosis membrane fouling, Exp. Thermal Fluid Sci., 14 (1997) 382-391.

[3] M.Kumar, S.S. Adham and W.R. Pearce, Investigation of seawater reverse osmosis fouling and its relationship to pretreatment type, Environ. Sci. Technol., 40 (2006) 2037-2044.

[4] K.E. Cooksey and B. Wigglesworth-Cooksey, Adhesion of bacteria and diatoms to surfaces in the sea: a review, Aquat. Microb. Ecol., 9 (1995) 87-96.

[5] C.Gomez-Suarez, J. Pasma, A.J. van der Borden, J. Wigender, H-C Flemming, H.J. Busscher and H.C. van der Mei, Influence of extracellular polymeric substances on deposition and redeposition of Pseudomonas aeruginosa to surfaces, Microbiology, 148 (2002) 1161-1169.

[6] M.D. Kennedy, H.K. Chun, V.A. Q. Yangali, B.G.J. Heij and J.C. Schippers, Natural organic matter (NOM) fouling of ultrafiltration membranes: fractionation of NOM in surface water and characterisation by LC-OCD, Desalination, 178 (2005) 73-83.

[7] G. Amy, Fundamental understanding of organic matter fouling of membranes, Desalination, 231 (2008) 44-51.

[8] M.D. Kennedy, J. Kamanyia, B.G.J. Heijman and G. Amy, Colloidal organic matter fouling of UF membranes: role of NOM composition and size. Desalination, 220 (2008) 200-213.

[9] S. Lee and M. Elimelech, Relating organic fouling of reverse osmosis membranes to intermolecular adhesion forces, Environ. Sci. Technol., 40 (2006) 980-987.

[10] W.S. Ang, S. Lee and M. Elimelech, Chemical and physical aspects of cleaning of organic-fouled reverse osmosis membranes, J. Membr. Sci., 272 (2006) 198-210.

[11] H-C. Flemming, T.R. Neu and D.J. Wozniak, The EPS Matrix: The "House of biofilm cells". J. Bacteriol., 189 (2007) 7945-7947. 
[12] R.J. Palmer, Jr. and P.Stoodley, Biofilms 2007: Broadened horizons and new emphases. J. Bacteriol., 189 (2007) 7948-7960.

[13] T. Berman and M. Holenberg, Don't fall foul of biofilm through high TEP levels, Filtr. Sep., 42(4) (2005) 30-32.

[14] T. Berman and U. Passow, Transparent exopolymer particles (TEP): an overlooked factor in the process of biofilm formation in aquatic environments, Nature Proc., 2007, http://dx.doi.org/ 10.1038/npre.2007.1182.1.

[15] A.L .Alldredge, U. Passow and B.E. Logan, The abundance and significance of a class of large, transparent organic particles in the ocean. Deep-Sea Res., 40 (1993) 1131-1140.

[16] U. Passow, Transparent exopolymer particles (TEP) in aquatic environments, Progr. Oceanogr., 55(3-4) (2002) 287-333.

[17] D.C.O. Thornton, E.M. Fejes, S.F. DiMarco and K.M. Clancy, Measurement of acid polysaccharides in marine and freshwater samples using Alcian Blue. Limnol. Oceanogr. Methods, 5 (2007) 73-87.

[18] X. Mari, Carbon content and C:N ratio of transparent exopolymeric particles (TEP) produced by bubbling exudates of diatoms. Mar. Ecol. Prog. Ser., 183 (1999) 59-71.

[19] U. Passow, Formation of transparent exopolymer particles, TEP from dissolved precursor material, Mar. Ecol. Prog. Ser., 192 (2000) $1-11$.

[20] K. Mopper, J. Zhou, K.S. Ramana, U. Passow, H.G. Dam and D.T. Drapeau, The role of surface-active carbohydrates in the flocculation of a diatom bloom in a mesocosm. Deep Sea Res. II, 42 (1995) 47-73.

[21] J. Zhou, K. Mopper and U. Passow, The role of surface-active carbohydrates in the formation of transparent exopolymer particles by bubble adsorption of seawater. Limnol. Oceanog. 43(8) (1998) 1860-1871.

[22] U. Passow, Production of transparent exopolymer particles (TEP) by phyto- and bacterioplankton, Mar.Ecol.Prog. Ser., 236 (2002) $1-12$.

[23] K.E. Stoderegger and G.J. Herndl, Production of exopolymer particles by marine bacterioplankton under contrasting turbulence conditions, Mar. Ecol. Prog. Ser.,189 (1999) 9-16.

[24] T. Berman and Y. Viner-Mozzini, Abundance and characteristics of polysaccharide and proteinaceous particles in Lake Kinneret. Aquat. Microb. Ecol., 24(3) (2001) 255-264.

[25] I. Berman-Frank, G. Rosenberg, O. Levitan, L. Haramaty and $X$. Mari, Coupling between autocatalytic cell death and transparent exopolymeric particle production in the marine cyanobacterium Trichodesmium. Environ. Microbiol., 9(6) (2007) 14151422.

[26] P. Verdugo, A.L. Alldredge, F. Azam, D. Kirchman, U. Passow and P.Santschi, The oceanic gel phase: a bridge in the DOM-POM continuum, Mar.Chem., 92 (2004) 67-85.
[27] X. Mari and H.G. Dam, Production, concentration and isolation of transparent exopolymer particles using parmagnetic functionalized microspheres, Limnol. Oceanog. Methods, 2 (2004) $13-24$.

[28] A. Engel, Distribution of transparent exopolymer particles (TEP) in the northeast Atlantic Ocean and their potential significance for aggregation processes, Deep-Sea Research Part I: Oceanographic Research Papers, 51(1) (2004) 83-92.

[29] U. Passow and A.L. Alldredge, Distribution, size and bacterial colonization of transparent exopolymer particles (TEP) in the ocean, Mar. Ecol. Prog. Ser., 113 (1994) 185-198.

[30] X. Mari and T. Kiørboe, Abundance, size distribution and bacterial colonization of transparent exopolymeric particles (TEP) during spring in the Kattegat, J. Plankton Res.,18 (1996) 969-986.

[31] J-F.Carrias, J. Serre, T. Sime-Ngando and C. Amblard, Distribution, size and bacterial colonization of pico- and nano-detrital organic particles in two lakes of different trophic status. Limnol. Oceanog., 47 (2002) 1202-1209.

[32] R. Wotton, The essential role of exopolymers (EPS) in aquatic systems. Oceanogr. Mar. Biol.: Ann. Rev., 42 (2004) 57-94.

[33] P.V. Bhaskar and N.B. Bhosle, Microbial extracellular polymeric substances in marine biochemical processes, Current Sci., 88 (2005) 45-53.

[34] B. Mostajir, J.R. Dolan and F. Rassoulzadegan, A simple method for the quantification of a class of labile marine pico- and nanosized detritus: DAPI Yellow Particles ('DYP'), Aquat. Microb. Ecol., 9 (1995) 259-266.

[35] R.A. Long and F. Azam, Abundant protein-containing particles in the sea, Aquat. Microb. Ecol., 10(3) (1996) 213-221.

[36] U. Passow and A.L. Alldredge,. A dye-binding assay for the spectrophotometric measurement of transparent exopolymer particles (TEP), Limnol. Oceanogr., 40(7) (1995) 1326-1335.

[37] O.Holm-Hansen, C.J. Lorenzen, R.W.Holmes and J.D. Strickland Fluorometric determination of chlorophyll, J. Cons. Perm. Int. Explor. Mer., 30 (1965) 3-15.

[38] K.G. Porter and Y.S. Feig, The use of DAPI for identifying and counting aquatic microflora. Limnol.Oceanogr., 25 (1980) 943-948.

[39] M.E. Callow and J.A. Callow, Marinebiofouling: a sticky problem, Biologist, 49 (2002) 1-5.

[40] J.A. Jurcsek and L.O. Bakaletz, Biofilms formed by nontypeable Haemophilus influenze in vivo contain both double stranded DNA and type IV Pilin protein, J. Bact., 189 (2007) 3868-3875.

[41] S. Kjelleberg and S. Molin, Is there a role for quorum sensing signals in bacterial biofilms? Curr. Opin. Microbiol., 5 (2002) 254258 .

[42] M. Molin and T. Tolker-Nielsen, Gene transfer occurs with enhanced efficiency in biofilms and induces enhanced stabilization of the biofilm structure, Curr. Opin. Biotechnol., 14 (2003) 255261 